\title{
Association between CLN3 (neuronal ceroid lipofuscinosis, CLN3 type) gene expression and clinical characteristics of breast cancer patients
}

OPEN ACCESS

Edited by:

Saleh AlGhamdi,

King Saud bin Abdulaziz University For Health Sciences, Saudi Arabia

Reviewed by:

Parvin Mehdipour,

Tehran University of Medical

Sciences, Iran

Abdul-Mohsen Alhejaily,

King Fahad Medical City, Saudi Arabia

${ }^{*}$ Correspondence:

Rose-Mary Boustany,

Neurogenetics Program

and Pediatric Neurology,

Department of Pediatrics, Adolescent

Medicine and Biochemistry,

American University of Beirut,

P.O. Box 11-0236 Riad El Solh,

Beirut 1107 2020, Lebanon rb50@aub.edu.lb

${ }^{\dagger}$ Co-senior authors.

Specialty section: This article was submitted to Cancer Genetics, a section of the journal Frontiers in Oncology

Received: 20 August 2015 Accepted: 22 September 2015

Published: 12 October 2015

Citation:

Makoukii J, Raad M, Genadry K, El-Sitt S, Makhoul NJ, Saad Aldin E, Nohra $E$, Jabbour $M$,

Sangaralingam A, Chelala $C$,

Habib RH, Boulos F, Tfayli A and

Boustany R-M (2015) Association

between CLN3 (neuronal ceroid

lipofuscinosis, CLN3 type) gene expression and clinical characteristics of breast cancer patients. Front. Oncol. 5:215

doi: 10.3389/fonc.2015.00215
Joelle Makoukji ${ }^{1}$, Mohamad Raad ${ }^{1}$, Katia Genadry ${ }^{1}$, Sally El-Sitt' ${ }^{1}$, Nadine J. Makhoul ${ }^{1}$, Ehab Saad Aldin ${ }^{2}$, Eden Nohra ${ }^{3}$, Mark Jabbour ${ }^{4}$, Ajanthah Sangaralingam ${ }^{5}$, Claude Chelala ${ }^{5}$, Robert H. Habib ${ }^{6}$, Fouad Boulos ${ }^{4}$, Arafat Tfayli $^{3+}$ and Rose-Mary Boustany ${ }^{1,7+*}$

\footnotetext{
'Department of Biochemistry and Molecular Genetics, American University of Beirut Medical Center, Beirut, Lebanon, ${ }^{2}$ Department of Radiology, University of lowa Hospitals and Clinics, lowa City, IA, USA, ${ }^{3}$ Department of Internal Medicine, American University of Beirut Medical Center, Beirut, Lebanon, ${ }^{4}$ Department of Pathology and Laboratory Medicine, American University of Beirut Medical Center, Beirut, Lebanon, ${ }^{5}$ Centre for Molecular Oncology, Barts Cancer Institute, Queen Mary University of London, London, UK, ${ }^{6}$ Outcomes Research Unit, American University of Beirut Medical Center, Beirut, Lebanon, ${ }^{7}$ Neurogenetics Program, Division of Pediatric Neurology, Department of Pediatrics and Adolescent Medicine, American University of Beirut Medical Center, Beirut, Lebanon
}

Breast cancer is the most common cancer in women worldwide. Elucidation of underlying biology and molecular pathways is necessary for improving therapeutic options and clinical outcomes. CLN3 protein (CLN3p), deficient in neurodegenerative CLN3 disease is anti-apoptotic, and defects in the CLN3 gene cause accelerated apoptosis of neurons in CLN3 disease and up-regulation of ceramide. Dysregulated apoptotic pathways are often implicated in the development of the oncogenic phenotype. Predictably, CLN3 mRNA expression and CLN3 protein were up-regulated in a number of human and murine breast cancer-cell lines. Here, we determine CLN3 expression in non-tumor vs. tumor samples from fresh and formalin-fixed/paraffin-embedded (FFPE) breast tissue and analyze the association between CLN3 overexpression and different clinicopathological characteristics of breast cancer patients. Additionally, gene expression of 28 enzymes involved in sphingolipid metabolism was determined. CLN3 mRNA is overexpressed in tumor vs. non-tumor breast tissue from FFPE and fresh samples, as well as in mouse MCF7 breast cancer compared to MCF10A normal cells. Of the clinicopathological characteristics of tumor grade, age, menopause status, estrogen receptor, progesterone receptor, and human epidermal growth factor receptor 2 (HER2), only absence of HER2 expression correlated with CLN3 overexpression. Sphingolipid genes for ceramide synthases 2 and 6 (CerS2; CerS6), delta(4)-desaturase sphingolipid 2 (DEGS2), and acidic sphingomyelinase (SMPD1) displayed higher expression levels in breast cancer vs. control tissue, whereas ceramide galactosyltransferase (UGT8) was underexpressed in breast cancer samples. CLN3 may be a novel molecular target for cancer drug discovery with the goal of modulation of ceramide pathways.

Keywords: CLN3, breast cancer, HER2, ceramide, sphingolipid signaling 


\section{Introduction}

Globally, about 1.38 million women are diagnosed with breast cancer and 458,503 die from the disease every year (1). The incidence is rising in low-income and middle-income countries, a trend attributed to improved life expectancy, urbanization, and adoption of a Western diet and lifestyle (2-4). In Lebanon, breast cancer is now the leading cancer among women $(5,6)$ and contributes to $45 \%$ of annual registered deaths (5). Breast cancer in Lebanon manifests larger tumor size, more lymph node involvement, and higher tumor grades $(7,8)$.

CLN3p impacts cell-cell communication, apoptosis and autophagy, proper functioning of lysosomes, and galactosylceramide (GalCer) lipid transport from Golgi to lipid rafts in the plasma membrane (9). Defects in this gene lead to Juvenile Neuronal Ceroid Lipofuscinosis or CLN3 disease, a pediatric neurodegenerative disease (10). In CLN3 disease, defective or low levels of CLN3p lead to failure of GalCer transport to lipid rafts, thus impairing lipid raft function, and resulting in toxic increases in ceramide (9). This process leads to enhanced apoptosis of neurons and photoreceptors initiated via caspase- 8 activation $(9,11)$.

Cancer and neurodegeneration are often two sides of the same coin. Low levels of CLN3p lead to neurodegeneration and enhanced apoptosis, and high levels of CLN3p may lead to inhibition of apoptosis, cellular proliferation, and carcinogenesis. The expression of CLN3 mRNA and CLN3 protein is increased in a variety of cancers, including prostate, ovarian, colon, glioblastoma, and, human breast cancer-cell lines and solid colon cancer (Figure S1 in Supplementary Material) (12). High levels of CLN3 are linked to inhibition of apoptosis by negatively impacting ceramide generation upstream $(11,13)$. Moreover, blocking CLN3 expression using anti-sense strategies led to cancercell killing, suggesting CLN3p may be a potential therapeutic target (12).

There is increasing evidence for the involvement of sphingolipid signaling in breast cancer (14). Sphingolipids are a family of lipids lending structural support to the membrane bilayer (15). Also, sphingolipid-regulated functions have significant and specific links to various aspects of cancer initiation, progression, and response to anticancer treatments. Ceramide, in particular, is intimately involved in the regulation of cancer-cell growth, differentiation, senescence, and apoptosis (16).

In this study, levels of CLN3 expression in 75 paired invasive ductal carcinomas (IDC) and their corresponding non-tumor freshly dissected breast tissues and another 189 breast cancer tissue paraffin blocks and corresponding normal tissue paraffin blocks from the same patient are compared by quantitative realtime polymerase chain reaction (qRT-PCR). The association of CLN3 expression with specific clinicopathological characteristics of breast cancer patients is documented. In addition, gene expression of enzymes controlling sphingolipid metabolism in fresh-frozen breast cancer tissues is established, confirming the CLN3-ceramide link.

\section{Materials and Methods}

\section{Specimen Collection}

A total of 75 patients with IDC of the breast were subjected to surgical resection at the American University of Beirut Medical Center, between September 2012 and May 2014. Fresh breast cancer and corresponding non-tumor breast samples were collected and stored in RNAlater $^{\mathrm{TM}}$ (Qiagen) at $-20^{\circ} \mathrm{C}$. AUB-IRB (American University of Beirut - Institutional Review Board) approved our study (IRB number: IM.AT.05, last updated on May 27th, 2013). Written informed consent was obtained from patients following this AUB-IRB-approved protocol, and in accordance with the Declaration of Helsinki. Additionally, formalin-fixed/paraffinembedded (FFPE) breast tissue blocks from 7 patients who underwent reduction mammoplasty and from 189 patients (paired IDC and their corresponding non-tumor breast tissue blocks) were obtained from the Department of Pathology of the American University of Beirut Medical Center, also under an AUBIRB-approved protocol. All samples were used for detection of CLN3 mRNA expression. Patient clinicopathological characteristics were tabulated, including tumor grade, age, menopause, estrogen receptor (ER), progesterone receptor (PR), and human epidermal growth factor receptor 2 (HER2) status.

\section{mRNA Expression Levels}

Formalin-fixed/paraffin-embedded tissue samples were cut into $20 \mu \mathrm{m} \times 10 \mu \mathrm{m}$ sections to be included per extraction. FFPE sections were deparaffinized using xylene and lysed overnight in proteinase $\mathrm{K}$. Then, mRNA was extracted using the RiboZol ${ }^{\mathrm{TM}}$ RNA Extraction Reagent (Amresco) according to the manufacturer instructions. RNA was eluted in nuclease-free water and stored at $-80^{\circ} \mathrm{C}$ until use. RNA was treated with DNase enzyme (Fermentas) to remove genomic DNA. Using RNeasy ${ }^{\circledR}$ Plus Mini Kit (Qiagen), total RNA was extracted from human fresh breast tissues, according to the manufacturer's protocol. For assessing RNA quality and yield, $A_{260} / A_{280}$ and $A_{260} / A_{230}$ ratios for RNA were analyzed with a NanoDrop ${ }^{\circledR}$ ND-1000 spectrophotometer (NanoDrop Technologies) and Experion ${ }^{\mathrm{TM}}$ Automated Electrophoresis System (BioRad), respectively.

RNA was reverse transcribed using RevertAid Reverse Transcriptase (Thermo Scientific) with 100-1000 ng of input RNA and random primers (Thermo Scientific). Quantitative real-time PCR reactions were performed in 96-well plates using specific primers (TIB MOLBIOL) and the $\mathrm{iQ}^{\mathrm{TM}} \mathrm{SYBR}^{\circledR}$ Green Supermix (BioRad) as a fluorescent detection dye, in CFX96 ${ }^{\mathrm{TM}}$ Real-Time PCR (BioRad), in a final volume of $12.5 \mu \mathrm{l}$. To characterize generated amplicons and to control contamination by unspecific byproducts, melt-curve analysis is applied. Each reaction was performed in duplicate. All results were normalized to PGK1 mRNA level and calculated using the $\Delta \Delta C_{\mathrm{T}}$ method. The specificity of the PCR was determined by melt-curve analysis for each reaction. Primer sequences are listed in Table S1 in Supplementary Material $\left(T_{\mathrm{m}}=60^{\circ} \mathrm{C}\right)$.

\section{Cell Culture}

Human breast adenocarcinoma or MCF7 cells (ATCC) were grown at $37^{\circ} \mathrm{C}$ under $5 \% \mathrm{CO}_{2}$ in RPMI 1640 medium 
supplemented with $10 \%$ heat-inactivated fetal bovine serum (FBS) and $1 \%$ penicillin-streptomycin. Human breast epithelial or MCF10A cells (ATCC) were maintained at $37^{\circ} \mathrm{C}$ in a humidified atmosphere of $5 \% \mathrm{CO}_{2} / 95 \%$ air in DMEM/F12 medium supplemented with $5 \%$ heat-inactivated horse serum, $10 \mu \mathrm{g} / \mathrm{ml}$ insulin, and $100 \mathrm{mg} / \mathrm{ml}$ Cholera toxin, $0.5 \mu \mathrm{g} / \mathrm{ml}$ hydrocortisone, $20 \mathrm{ng} / \mathrm{ml}$ recombinant EGF, and $1 \%$ penicillin-streptomycin. Medium was changed every 2 days, and cells were split every week.

\section{SiRNA CLN3 Knockdown}

siRNA for CLN3 knockdown (BLOCK-iT RNA ${ }^{\mathrm{TM}}$ Designer, Invitrogen) or scrambled control were transfected into MCF7 cells (HiPerfect Transfection, Qiagen). Cell pellets are collected on day 4 to measure ceramide levels using the diacylglycerol kinase (DGK) assay. For validation of CLN3 knockdown, quantitative real-time PCR reactions were performed. Results were normalized to Cyclophyllin A mRNA level and calculated using the $\Delta \Delta C_{\mathrm{T}}$ method. Primer sequences are listed in Table S1 in Supplementary Material $\left(T_{\mathrm{m}}=60^{\circ} \mathrm{C}\right)$.

\section{Trypan Blue Dye Exclusion Method}

Cell growth and viability was determined using trypan blue dye exclusion. About 100,000 MCF7 cells are seeded per well and transfected with CLN3 siRNA/scrambled siRNA. After $96 \mathrm{~h}$, cells were washed, centrifuged, and fresh media added. The cells are then stained with trypan blue dye $(0.4 \%)$ and the number of white viable and dead blue cells is counted using a light microscope and a hemocytometer.

\section{Propidium lodide Staining}

About 100,000 MCF7 cells are transfected with CLN3 siRNA/scrambled siRNA, suspended in $100 \mu \mathrm{l}$ PBS, incubated with $100 \mu \mathrm{l} / 0.5 \mathrm{mg} / \mathrm{ml} \mathrm{PI}$, washed, placed on slides, and viewed with a fluorescent microscope. Cells are harvested 72 and $96 \mathrm{~h}$ after transfection. Three hundred cells in three different fields of vision were counted, and percentage of red staining apoptotic cells/total cells determined.

\section{Measurement of Ceramide Levels Cell Homogenization}

Cell pellets were collected and washed with PBS, then suspended in methanol/chloroform $(2: 1)$ and stored at $-80^{\circ} \mathrm{C}$ for $48 \mathrm{~h}$.

\section{Lipid Extraction}

Seven hundred microliters of distilled water are added to the homogenate, then $1 \mathrm{ml}$ chloroform and $1 \mathrm{ml}$ of distilled water, and the sample centrifuged for $10 \mathrm{~min}$ at $4^{\circ} \mathrm{C}$. The lower phase is lyophilized. Lipids are resuspended in $1 \mathrm{ml}$ chloroform.

\section{Ceramide Assay}

Ceramide standards and samples are dried using a speedvac. Micelles were added to samples/standards and sonicated for three cycles of $30 \mathrm{~min}$ each. Reaction mixtures are added to the ATP mix and incubated at RT for $45 \mathrm{~min}$. The reaction is stopped using methanol/chloroform/distilled water, then lipids extracted. These are run on a TLC plate using chloroform/acetone/methanol/acetic acid/water (50:20:15:10:5). Plates are then dried, $\mathrm{x}$-ray film overlaid and kept at $-80^{\circ} \mathrm{C}$ overnight. Ceramide bands are visualized, scraped into scintillation vials, and counts per minute detected using a liquid scintillation counter. The results are expressed as picomoles of ceramide per nanomole of total phospholipids.

\section{Phosphate Determination}

After lyophilization, $150 \mu \mathrm{l}$ of $70 \%$ perchloric acid are added to samples and to disodium hydrogen phosphate $\left(\mathrm{Na}_{2} \mathrm{HPO}_{4}\right)$ standards. Tubes are capped with glass balls previously soaked in methanol and placed at $180^{\circ} \mathrm{C}$ for $1 \mathrm{~h}$, cooled at RT and distilled water $/ 2.5 \%$ ammonium molybdate $/ 10 \%$ ascorbic acid added. Mixtures are incubated for $15 \mathrm{~min}$ at $50^{\circ} \mathrm{C}$, and concentration determined with a spectrophotometer ( $820 \mathrm{~nm}$ wavelength).

\section{Microarray Expression Profiling and Data Analysis}

Gene expression analysis was performed on 94 fresh breast tissue samples (84 cancerous and 10 normal) using the GeneChip Human Genome U133 Plus 2.0 arrays (Affymetrix Inc.) representing over 45,000 transcripts. Samples were prepared and microarrays were processed using the GeneChip $3^{\prime}$ IVT Express kit as instructed by the manufacturer. Briefly, $100 \mathrm{ng}$ of total RNA are fragmented then hybridized to the arrays. After washing and staining using the GeneChip Fluidics Station 450, the arrays are scanned with the GeneChip Scanner 3000 7G. Cell intensity data (CEL) files are generated with the Affymetrix GeneChip Command Console (AGCC) software version 3.2.

Data were analyzed within the $\mathrm{R}$ statistical environment (17) using Bioconductor (http://www.bioconductor.org) packages. Stringent quality control criteria were applied to the data. Three samples were found to be of a low quality and were excluded of subsequent analyses. Data were normalized jointly with the Robust Multiarray Average (RMA) algorithm (18).

Where more than one probe was found to match the same gene the mean expression value was calculated and used. Expression boxplots for the genes of interest of tumor against normal samples were generated from this expression matrix.

To detect differentially expressed genes between tumor and normal samples, Limma (19) was used to fit a linear model to normalized expression data for each probe. False discovery rates (FDRs) were estimated using the Benjamini-Hochberg method (20).

\section{Statistical Analysis}

CLN3 mRNA expression was quantified in breast adenocarcinomas and overexpression was defined as a 1.25 -fold increase in expression compared to normal tissue. Continuous data were expressed as means \pm SEM, whereas categorical data were summarized as counts and percents. The chi-square $\left(\chi^{2}\right)$ test for categorical variables was used to determine the association between gene expression levels and clinicopathological characteristics. Means of continuous data were compared by the two-tailed Student's $t$-test. For multiple group comparisons, two-way ANOVA followed by Bonferroni's correction was used. Gene expression data derived by Affymetrix or real-time PCR were compared for tumor vs. normal tissue by standard $t$-test. The concordance or 
discordance between normal breast tissue adjacent to the tumor and normal breast tissue from reduction mammoplasties was analyzed using the kappa $(\kappa)$ test of concordance. Concordances of $<0.40,0.40-0.75$, and $>0.75$ were defined as poor, moderate, and perfect, respectively.

SPSS statistical software version 21.0 (SPSS Inc., Chicago, IL, USA) was used for analysis, except for the Affymetrix expression data that were analyzed using $\mathrm{R}$ statistical environment. All tests were two-sided and $p<0.05$ was considered as a statistically significant difference.

\section{Results}

\section{Patient Characteristics}

Of the 189 patient malignant FFPE tissues from breast adenocarcinomas, only 175 had corresponding non-tumor FFPE tissue. Of these 175 patients, 21, 49, 51, and 54 patients had Ductal Carcinoma In Situ (DCIS), or IDC grades I, II, and III, respectively. A total of 26 were $<40$ years, 56 were between 40 and 49 years, 66 were between 50 and 69 years, 22 were $>70$ years old. In five patients, age was undetermined. Eighty-three were menopausal, 87 were premenopausal and menopausal status was undetermined in 5 patients. ER was positive in 128 patients, negative in 31 . Information on another 16 patients was not available. PR was positive in 105 , negative in 51 , and undetermined in 19 patients. Thirty-two were HER2 positive, 108 were HER2 negative and information on an additional 35 patients was not available.

The malignant FFPE tissue from 189 patients was compared to non-tumor FFPE tissue collected from 7 reduction mammoplasties. Of those, $22,50,57$, and 60 patients had DCIS, and IDC grades I, II, and III, respectively. A total of 29 were $<40$ years, 58 were between 40 and 49 years, 68 were between 50 and 69 years, 28 were $>70$ years old, whereas in 6 patients, age was undetermined. Ninety-one were menopausal, 92 were premenopausal and menopausal status was undetermined in 6 patients. ER was positive in 139 and negative in 33 patients. Information on 17 patients was not available. PR was positive in 114, negative in 55 and undetermined in 20 patients. Thirty-five were HER2 positive and 117 patients were HER2 negative. Information on 37 patients was not available. Clinical characteristics of the patients are summarized in Table $\mathbf{1}$.

Patient clinicopathological characteristics and their frequencies from IDC of the breast and non-tumor tissue (from same patient or from reduction mammoplasties) were compared. The table also displays the frequency distribution and percentage of the two variables: CLN3 overexpression and patient clinicopathological characteristics. Statistics were calculated by the Pearson $\chi^{2}$ test and undetermined samples were not included. CLN3 expression levels were analyzed by comparing malignant tissue from breast adenocarcinomas to corresponding non-tumor tissue. The cut-off point for $C L N 3$ overexpression was a 1.25-fold increase. A $p<0.05$ was considered as statistically significant.

\section{CLN3 Gene Expression}

To determine the potential role of CLN3 in the development and progression of IDC of the breast, 75 paired fresh tumor tissues and 189 paired FFPE IDC breast samples were collected and
TABLE 1 | Relationship between CLN3 mRNA overexpression and patient clinicopathological parameters of the FFPE breast carcinoma tissue.

\begin{tabular}{|c|c|c|c|c|c|c|}
\hline \multirow[t]{2}{*}{ Variable } & \multicolumn{3}{|c|}{$\begin{array}{c}\text { Cancer vs. } \\
\text { normal tissue } \\
\text { from } \\
\text { same patient }\end{array}$} & \multicolumn{3}{|c|}{$\begin{array}{c}\text { Cancer vs. } \\
\text { normal tissue } \\
\text { from reduction } \\
\text { mammoplasty }\end{array}$} \\
\hline & Number & $\begin{array}{c}\text { CLN3 } \\
\text { Over- } \\
\text { expression }\end{array}$ & $p$ & Number & $\begin{array}{c}\text { CLN3 } \\
\text { Over- } \\
\text { expression }\end{array}$ & $p$ \\
\hline \multicolumn{7}{|l|}{ Tumor grade } \\
\hline DClS & 21 & 8 & 0.549 & 22 & 11 & 0.954 \\
\hline IDC grade I & 49 & 24 & & 50 & 27 & \\
\hline IDC grade II & 51 & 21 & & 57 & 31 & \\
\hline IDC grade III & 54 & 19 & & 60 & 30 & \\
\hline \multicolumn{7}{|l|}{ Age (years) } \\
\hline$<40$ & 26 & 6 & 0.206 & 29 & 16 & 0.995 \\
\hline $40-49$ & 56 & 26 & & 58 & 30 & \\
\hline $50-69$ & 66 & 29 & & 68 & 36 & \\
\hline $70+$ & 22 & 8 & & 28 & 14 & \\
\hline Undetermined & 5 & & & 6 & & \\
\hline \multicolumn{7}{|l|}{ Menopause } \\
\hline Premenopausal & 87 & 46 & 0.301 & 92 & 45 & 0.334 \\
\hline Menopausal & 83 & 37 & & 91 & 51 & \\
\hline Undetermined & 5 & & & 6 & & \\
\hline \multicolumn{7}{|c|}{ Estrogen receptor } \\
\hline Negative & 31 & 12 & 0.845 & 33 & 16 & 0.429 \\
\hline Positive & 128 & 52 & & 139 & 73 & \\
\hline Undetermined & 16 & & & 17 & & \\
\hline \multicolumn{7}{|c|}{ Progesterone receptor } \\
\hline Negative & 51 & 18 & 0.677 & 55 & 25 & 0.232 \\
\hline Positive & 105 & 44 & & 114 & 63 (72\%) & \\
\hline Undetermined & 19 & & & 20 & & \\
\hline \multicolumn{7}{|l|}{ HER2 } \\
\hline Negative & 108 & 49 & 0.270 & 117 & 66 & $0.045^{\star}$ \\
\hline Positive & 32 & 11 & & 35 & 13 & \\
\hline Undetermined & 35 & & & 37 & & \\
\hline
\end{tabular}

Patient clinicopathological characteristics and their frequency. These frequencies are used when comparing IDC of the breast to corresponding non-tumor tissue (from same patient or from reduction mammoplasty). The table also displays the frequency distribution and percentage of the two variables: CLN3 overexpression and patient clinicopathological characteristics. Statistics were calculated by the Pearson $\chi^{2}$ test and undetermined samples were not included. CLN3 expression levels were analyzed by comparing malignant tissue from breast adenocarcinomas to corresponding non-tumor tissue. The cut-off point for CLN3 overexpression was a 1.25-fold increase.

${ }^{*} p<0.05$ was considered as statistically significant. Italics font means statistically significant.

characterized for the relative levels of CLN3 mRNA transcripts by qRT-PCR. When comparing FFPE IDC breast samples to the corresponding non-tumor tissue, $38 \%$ of the DCIS cases showed overexpression of the CLN3 gene. Overexpression of CLN3 was highest in IDC grade I (49\%). CLN3 expression was less prevalent in IDC grade II (41\%) and even less in IDC grade III (35\%). When comparing IDC breast samples to non-tumor tissue from reduction mammoplasty patients, overexpression of CLN3 was most prevalent for IDC grades I and II (54\%), and 50\% in DCIS and also $50 \%$ in IDC grade III. There is an increase in percentages of CLN3 overexpression when tumor tissue is compared to tissue from reduction mammoplasties as opposed to normal tissue from the same patient removed at surgery (Figure 1A).

Also in fresh tissue, $50 \%$ of IDC grade I cases showed overexpression of the CLN3 gene. Prevalence of CLN3 overexpression is highest in IDC grade II (67\%), followed by a decrease in IDC 

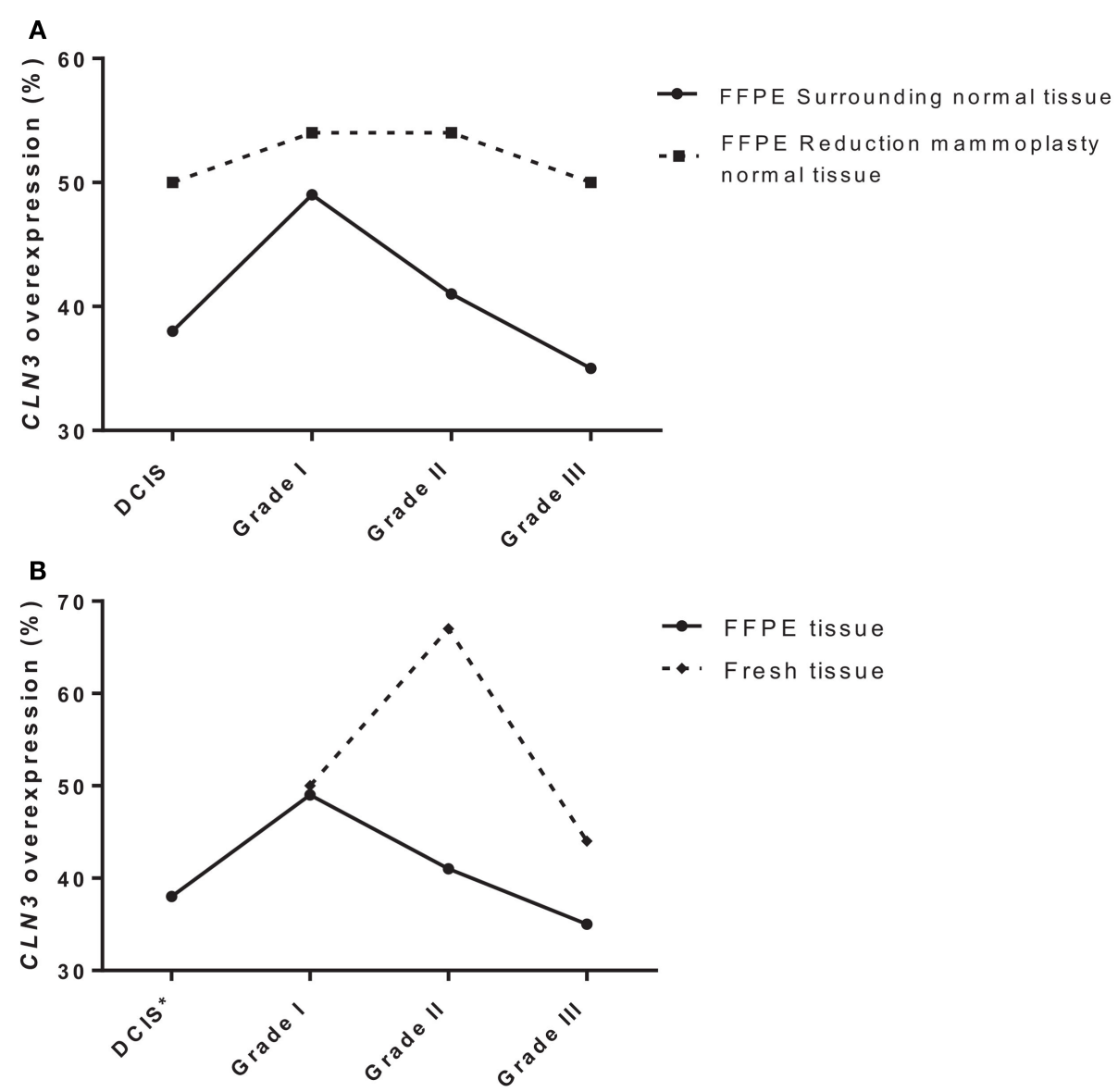

*No fresh tissue DCIS samples were available

FIGURE 1 | Expression of CLN3 in breast adenocarcinoma samples (A) FFPE breast cancer tissue of different tumor grades (DCIS, IDC grades I, II, and III) were collected with surrounding normal tissue and normal tissue from reduction mammoplasties. Total RNA was extracted and quantitative real-time PCR experiments were performed using primers for the CLN3 gene. The RT-PCR was normalized using PGK1 RNA. The cut-off point for CLN3 overexpression was a 1.25-fold increase. (B) Fresh and FFPE breast tissue of different tumor grades (DCIS, IDC grades I, II, and III) were collected with surrounding normal tissue. Total RNA was extracted and quantitative real-time PCR experiments were performed using primers for the CLN3 gene. The RT-PCR was normalized using PGK1 RNA. The cut-off point for CLN3 overexpression was a 1.25-fold increase.

grade III (44\%). Note the difference in percentages of CLN3 overexpression in FFPE tissue $(49,41$, and 35\%) for IDC grades I, II, and III, respectively. Higher percentages of CLN3 overexpression are observed in fresh breast tissue, as compared to FFPE tissue (Figure 1B).

\section{CLN3 Gene Expression Levels and Clinicopathological Characteristics}

CLN3 overexpression did not correlate with lower or higher tumor grade, age, menopausal status, ER, PR, and HER2 expression, when comparing the level of CLN3 mRNA between breast cancer and the surrounding non-tumor tissue (Table 1).

When comparing cancerous tissue to non-tumor tissue from reduction mammoplasties, no positive correlation was observed with respect to CLN3 overexpression and higher tumor grades, age, and menopause status. Similarly, there was no significant difference in CLN3 overexpression between patients with negative or positive ER and PR status. CLN3 overexpression in patients with no HER2 expression was significantly higher compared to those with positive HER2 breast cancer $(p=0.045)$ (Table 1). In fact, the cross-tabulation displaying the frequency distribution of the two variables (CLN3 mRNA expression and HER2 status) shows that when HER2 is not expressed, CLN3 is overexpressed in 66/117 (56\%) of cases, whereas, when HER2 is overexpressed, CLN3 is overexpressed in only 13/35 (37\%) of cases (Table 1). So, $56 \%$ of breast cancer patients that exhibit overexpression of CLN3 mRNA lack HER2 expression compared to only $37 \%$ overexpressing HER2 (Figure S2A in Supplementary Material). Fifteen percent of those cases overexpressing CLN3 and lacking HER2 receptor are triple negative (HER2/ER/PR negative) and $85 \%$ are ER/PR positive (Figure S2B in Supplementary Material).

\section{Growth, Apoptosis Rate, and Ceramide Levels in CLN3-Deficient MCF7 Cells}

CLN3 mRNA is overexpressed 3.5-fold in MCF7 cells compared to MCF10A cells, making MCF7 cells an excellent in vitro model to study the impact of CLN3 expression in breast cancer (Figure 2A). A significant blocking of CLN3 protein expression using CLN3 

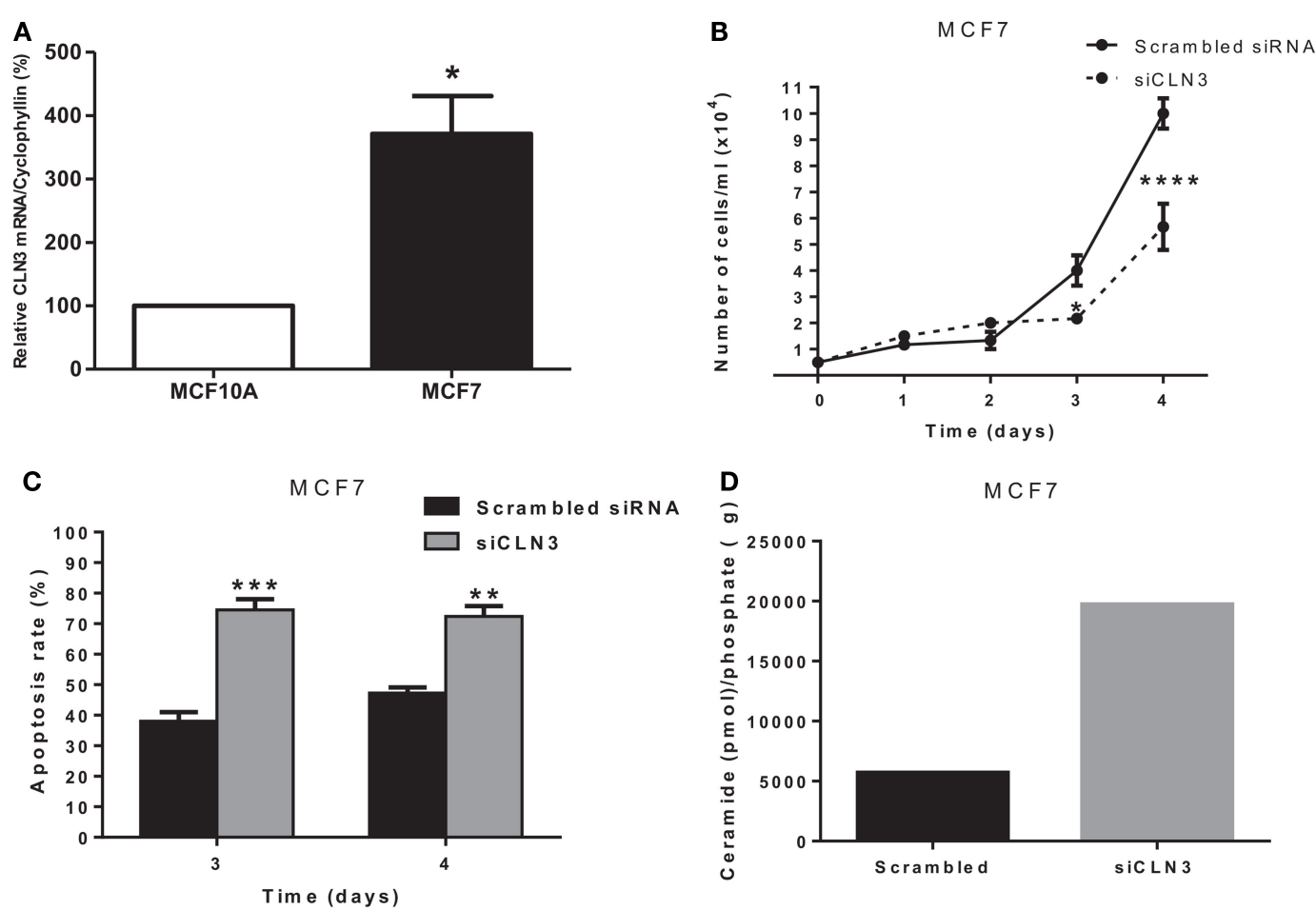

FIGURE 2 | CLN3 expression, growth, apoptosis rate, and ceramide level in MCF7 cells. (A) Total RNA was extracted from MCF7 and MCF10A cells and quantitative real-time PCR experiments were performed using primers for the CLN3 gene. The RT-PCR was normalized using Cyclophyllin $A$ and the results represent the mean \pm SEM of at least three independent experiments. ${ }^{*} p<0.05$ by two-tailed Student's $t$-test. (B) MCF7 cells were transfected with scrambled siRNA or with siRNA directed against CLN3 (siCLN3) for 4 days. Live cells were counted in triplicates at different time points. The results represent the mean \pm SEM of at least three independent experiments. ${ }^{*} p<0.05$ and ${ }^{\star \star \star \star} p<0.0001$ by two-way ANOVA followed by Bonferroni post test. (C) Propidium iodide positive cells were counted at different time points. The results represent the mean \pm SEM of three independent experiments. ${ }^{* \star} p<0.01$ and ${ }^{\star \star \star} p<0.001$ by two-way ANOVA followed by Bonferroni post test. (D) Ceramide levels are higher in cells transfected with siCLN3 as compared to those transfected with scrambled siRNA.

siRNA was achieved in MCF7 cells. Blocking CLN3 expression inhibited growth and viability of MCF7 cancer cells (Figure 2B), and increased apoptosis as shown by PI staining (Figure 2C). Previous work had shown that CLN3 negatively modulates ceramide generation in NT2 cells that are human teratocarcinoma-derived progenitor cells (21). Threefold higher levels of endogenous ceramide were observed after MCF7 cells were transfected with siRNA directed against CLN3 compared with control MCF7 cells transfected with scrambled siRNA (Figure 2D).

\section{Expression of Genes Involved in Sphingolipid Metabolism}

We used Affymetrix GeneChip Human Genome U133 Plus 2.0 expression arrays to determine differences in the mRNA expression of 28 genes involved in sphingolipid metabolism (Table S2 in Supplementary Material), in 83 cases of invasive breast cancer in fresh tissue compared to 8 non-tumor fresh breast tissue samples. Significant differences in the expression of several genes were observed in tumor samples vs. controls. Ceramide synthase 2 (CerS2) expression was 5-fold increased $(p=0.026)$, ceramide synthase 6 (CerS6) was 13.8 -fold increased $(p=0.001)$, delta(4)-desaturase sphingolipid 2 (DEGS2) was 5.5 -fold increased $(p=0.046)$, and acid sphingomyelinase (SMPD1) was increased 1.66-fold $(p=0.013)$. Neuronal Ceroid Lipofuscinosis $3(C L N 3)$ expression was also increased 3-fold $(p=0.077)$ and ceramide galactosyltransferase (UGT8) was 19.8fold decreased $(p=0.064)$, with an adjusted $p$-value close to significance (Figure 3A).

\section{Validation of Microarray Analysis Results with qRT-PCR}

The differential expression of the six selected genes was examined using qRT-PCR: CerS2, CerS6, DEGS2, SMPD1, CLN3, and UGT8. Results exhibited high consistency with those of the microarray analysis. Tumor status induced a significant increase in the expression of CerS2 $(p<0.0001)$, CerS6 $(p<0.0001)$, DEGS2 $(p<0.0001)$, SMPD1 $(p<0.05)$, and CLN3 $(p<0.0001)$; and a significant decrease in the expression of UGT8 $(p<0.0001)$ compared with expression in the corresponding non-tumor tissue (Figure 3B).

\section{Discussion}

In this study, CLN3 mRNA expression levels in breast cancer patient FFPE and fresh tissue samples were determined and association with patient characteristics established. The relative overexpression of CLN3 mRNA transcripts in IDC breast FFPE and fresh tissues was significantly higher than in surrounding control non-tumor tissues or in control non-tumor tissue from 


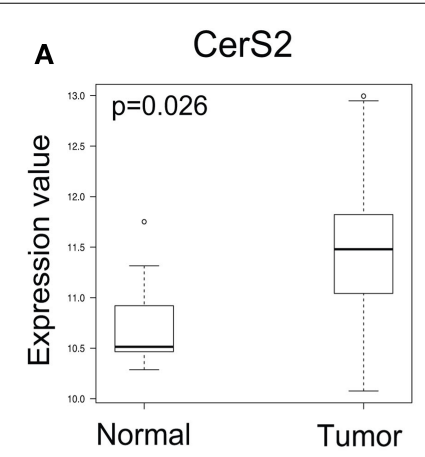

DEGS2

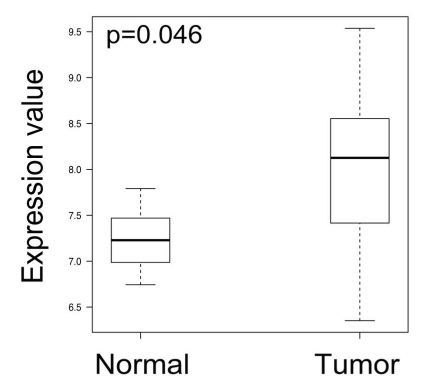

CLN3

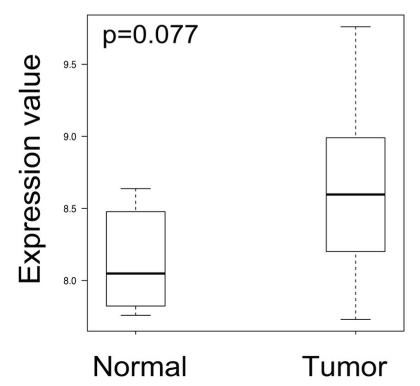

CerS6

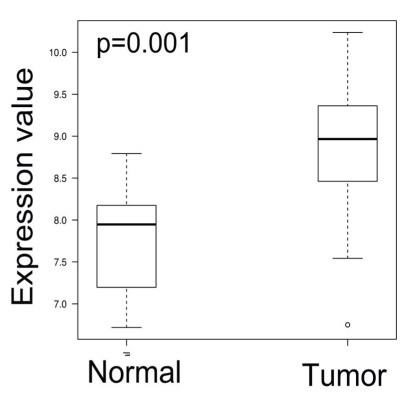

SMPD1

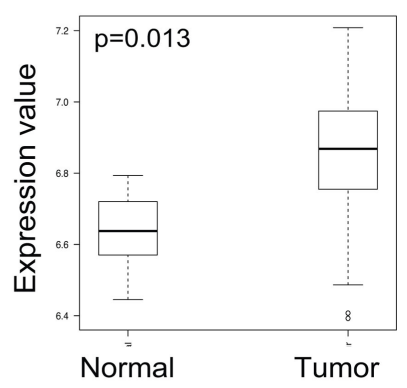

UGT8

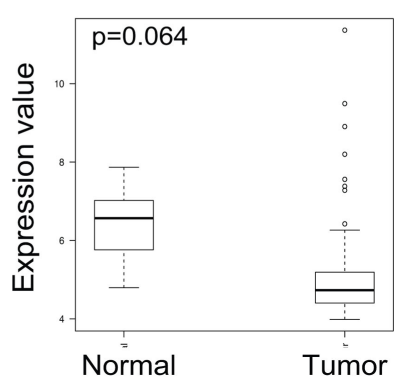

B

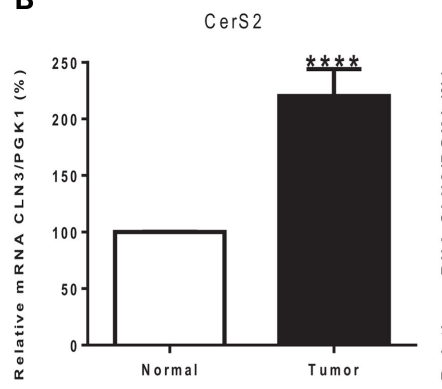

Cers 6

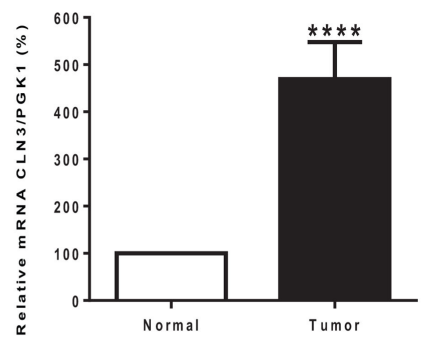

FIGURE 3 | Tumor status and expression of genes of interest. (A) Box plots of six genes of interest (CerS2, CerS6, DEGS2, SMPD1, CLN3, and UGT8) coding for enzymes involved in sphingolipid metabolism with differences in expression between normal and tumor tissue samples. The line in the middle of the boxplots represents the median in normal and tumor samples. ${ }^{*} p<0.05$ was considered as statistically significant. (B) Relative mRNA expression was measured by $\mathrm{RT}$-PCR. The following genes related to sphingolipid metabolism are ceramide synthase 2 (CerS2), ceramide synthase 6 (CerS6), delta(4)-desaturase sphingolipid 2 (DEGS2), acid sphingomyelinase (SMPD1), Neuronal Ceroid Lipofuscinosis 3 (CLN3), and ceramide galactosyltransferase (UGT8). Values are means of the fold changes normalized to PGK1 mRNA expression, with their SEs represented by vertical bars. ${ }^{*} p<0.05$ by Student's $t$-test $(n=34)$.

reduction mammoplasties. Furthermore, of the six clinicopathological parameters studied (tumor grade, age, menopause status, ER, PR, and HER2), CLN3 overexpression was significantly associated with absence of HER2 expression $(p=0.045)$ in patients with IDC of the breast (Table 2).

Receptor status is used as a guide to classify breast cancers into four biological subtypes: (a) low grade luminal A subtype, (b) high grade luminal B subtype (High grade, ER/PR positive or HER2+/ER+/PR +), (c) HER2 subtype (HER2+/ER-/PR-), and (d) triple negative/basal like subtype (HER2-/ER-/PR-) (22). So, the subtypes that are negative for HER2 receptor are luminal A, accounting for approximately $40 \%$ of all breast cancers and triple negative/basal like tumors that represent $10-20 \%$ of breast cancers and are negative, for all receptors. Lack of receptors limits the use of targeted treatments, such as hormonal therapy and anti-HER-2 agents, leading to a high proportion of disease-related death. The Human HER2 oncogene, also known as neu/c-erbB2, is responsible for encoding a $185-\mathrm{kDa}$ transmembrane receptor tyrosine kinase overexpressed in $20-30 \%$ of breast cancers and is associated with increased breast cancer recurrence and a worse prognosis (23). It is a member of the epidermal growth factor (EGF) receptor (EGFR) family. The use of trastuzumab (Herceptin ${ }^{\circledR}$ ), a humanized monoclonal antibody to the HER2 extracellular domain, improves survival in both early and metastatic HER2positive patients $(24,25)$. HER2 expression in breast cancer is associated with poor prognosis (26). Elevated expression of the CLN3 gene in breast cancer was significantly associated with HER2-negativity, when comparing cancerous to non-tumor tissue 
TABLE 2 | Results comparison between cell line, FFPE, and fresh breast tissue studies

\begin{tabular}{|c|c|c|c|}
\hline & Expression by qRT-PCR & Immunocytochemistry/immunohistochemistry & Western blot \\
\hline Breast cancer-cell data & $\begin{array}{l}\text { CLN3 mRNA overexpression in tumor MCF7 } \\
\text { cells compared to normal MCF10A cells }\end{array}$ & $\begin{array}{l}\text { More intense CLN3p staining in cultured BT20 breast } \\
\text { cancer tumor cells compared to normal cells (12) }\end{array}$ & $\begin{array}{l}\text { Overexpression } \\
\text { of CLN3p (12) }\end{array}$ \\
\hline FFPE breast tissue & $\begin{array}{l}\text { CLN3 mRNA overexpression in tumor tissue } \\
\text { (grades I, II, and III) compared to normal tissue }\end{array}$ & $\begin{array}{l}\text { Translocation of CLN3p from plasma membrane in normal } \\
\text { tissue to a more intense cytoplasmic CLN3 localization in } \\
\text { tumor tissue (Batoul Hassan Farran MS Thesis, AUB Saab } \\
\text { Medical Library, CLN3 expression in Breast cancer, 2010) }\end{array}$ & $\mathrm{N} / \mathrm{A}$ \\
\hline Fresh breast tissue & $\begin{array}{l}\text { CLN3 mRNA overexpression in tumor tissue } \\
\text { (grades I, II, and III) compared to normal tissue }\end{array}$ & N/A & $\mathrm{N} / \mathrm{A}$ \\
\hline
\end{tabular}

from reduction mammoplasties. Interestingly, only $15 \%$ of the cases overexpressing CLN3 and lacking HER2 receptor are triple negative (HER2/ER/PR negative) and $85 \%$ are ER/PR positive, indicating that up-regulated CLN3 could be a good prognostic factor in HER2-negative breast cancers, suggesting a broad application of CLN3 targeted therapies in breast cancers that do not overexpress HER2. To address the extent to which CLN3 could be a prognostic factor in breast cancer, the correlation between CLN3 expression and clinical disease outcomes, such as survival, recurrence, and metastasis, in different subtypes of breast cancer, would still need to be assessed.

Defects or diminished CLN3 protein expression in the juvenile form of CLN3 disease is associated with increased levels of the pro-apoptotic sphingolipid ceramide in brains and cells from these patients. Sphingolipids are bioactive lipids that play roles in the structure and regulation of cellular membranes, and also impact signaling acting as protagonists in neurodegenerative disease, inflammatory disease and cancer (27). Alterations in sphingolipid metabolism also contribute to chemoresistance and tumor survival (28). The central character in the sphingolipid pathway is ceramide. It is either synthesized de novo from serine and palmitate or generated by breakdown of sphingomyelin via different sphingomyelinases (29) (Figure 4). Of the different functions attributed to ceramide, special attention has been given to its pro-apoptotic properties (30), and its significance as a potential target for cancer chemotherapy (31). Previous work has shown that CLN3 is anti-apoptotic, and that diminishing levels of CLN3 protein in cancer cells enhances ceramide production and results in death of cancer cells (21). Ceramide is also produced in response to stress stimuli, including some chemotherapeutic drugs and irradiation (16). The cell death function of ceramide suggests that ceramide analogs may open doors to new therapies to battle cancer. Thus, finding ways to increase ceramide by exogenous treatment or by elevating endogenous ceramide in cancer cells becomes desirable. The role of sphingolipid signaling in HER2-negative breast cancer, however, is not yet well-defined.

We investigated whether a correlation exists between several elements of sphingolipid metabolism and tumor status in breast cancer in fresh tissue samples. Significant differences in tumor vs. control non-tumor tissue in the expression of many genes involved in this pathway were found. Ceramide synthase 2 (CerS2), ceramide synthase 6 (CerS6), delta(4)-desaturase, sphingolipid 2 (DEGS2), and acid sphingomyelinase (SMPD1) displayed higher expression in tumor samples. The alteration of these four enzymes may have several implications. First, dihydroceramide

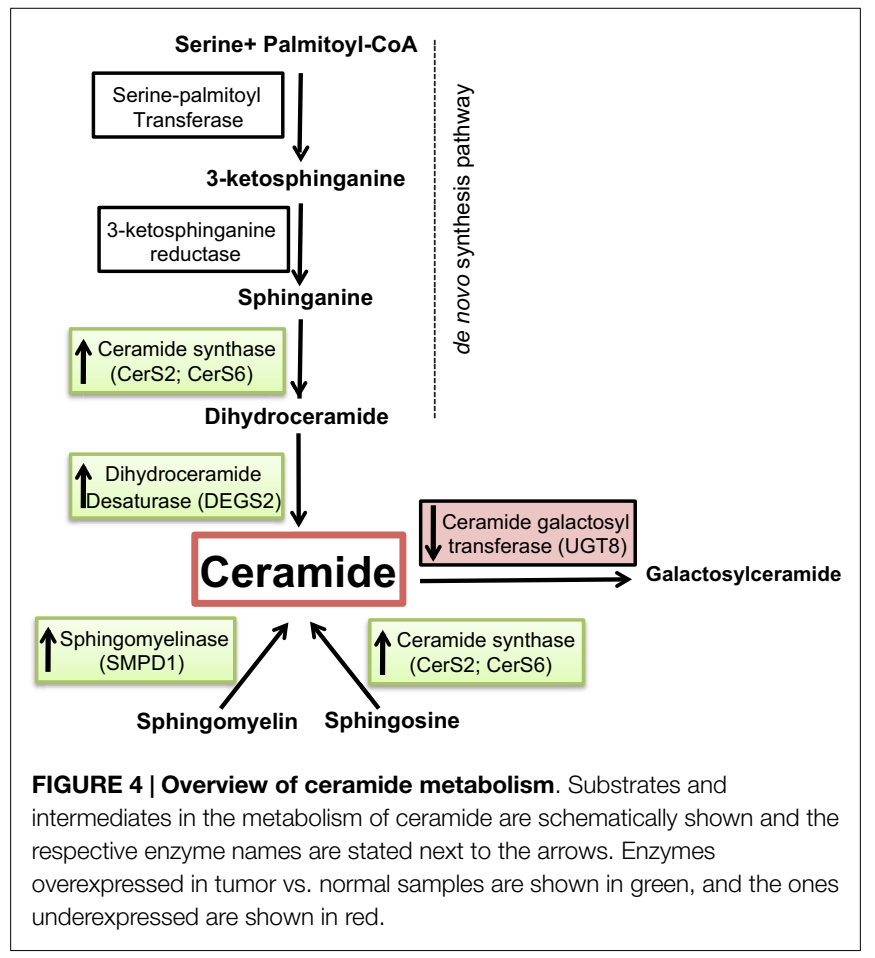

synthases (CerS2 and CerS6) acylate sphinganine and sphingosine to form dihydroceramide and ceramide, respectively (Figure 4). Erez-Roman et al. also determined that CerS2 and CerS6 mRNA expression is higher in human breast cancer tissue compared to paired normal tissue from the same patients (32). The hypothesis that higher levels of dihydroceramide synthases would directly or indirectly lead to higher levels of ceramide in tumor tissue may be an attempt to achieve a more efficient killing of cancer cells. The third enzyme dihydroceramide destaurase (DEGS) is responsible for the conversion of dihydroceramides generated via de novo biosynthesis to ceramides by the incorporation of a 4,5trans-double bond, a process occurring within the endoplasmic reticulum (33) (Figure 4). The indirect augmentation of dihydroceramides by siRNA blockade of DEGS1 or DEGS2 decreased cell proliferation (34). Inhibition of DEGS1 with siRNA in human neuroblastoma cells leads to the accumulation of endogenous dihydroceramides with subsequent effects on cell growth, particularly cell cycle arrest (35). The enzyme acid sphingomyelinase (SMase) catalyzes hydrolysis of sphingomyelin to ceramide and phosphocholine (Figure 4). To date, four SMases have been 
identified. SMPD1 encodes lysosomal acidic SMase, and three neutral SMases are coded for by SMPD2, SMPD3, and SMPD4, respectively (36). Osawa et al. show that acid sphingomyelinase (SMPD1) and ceramide levels are increased in metastatic liver tumors of colon cancer (37). Corcoran et al. demonstrate that neutral SMPD3 mRNA levels are increased in several tumor tissues when compared with their matching normal tissues (38). Ceramide galactosyltransferase (UGT8) showed lower expression in tumor tissue, but there is yet little information regarding its impact on cancer development. UGT8 encodes an endoplasmic reticulum-localized enzyme responsible for synthesis of galactosylceramide (GalCer) from ceramide (39). Altogether, the significant differences in the expression of CerS2, CerS6, DEGS2, SMPD1, and UGT8 sphingolipid genes in tumor tissue go hand in hand with elevation of ceramide levels (Figure 4). Ceramide is a well-established growth-inhibitory molecule, and up-regulation of growth-inhibitory molecules in human malignancies is not without precedence. Tumor necrosis factor-related apoptosis-inducing ligand is up-regulated in colon cancer, and this increase is associated with higher-grade tumors and a poorer prognosis (40). It is more plausible that up-regulation of specific sphingolipid enzyme mRNA expression in tumors could be a positive compensatory response by the cell as an attempt to increase ceramide production (Figure 5).

Breast tumorigenesis is a multistep process going from benign and atypical hyperproliferation, to in situ carcinoma, invasive carcinomas, and culminates in metastatic disease (41). The development and progression of breast cancer is a complex process attributable to the interaction of many genetic, epigenetic, and environmental factors. Altered gene expression profiles may drive disease progression (42). Breast cancer-overexpressed gene 1 (BCOX1) mRNA transcripts are detected in breast cancer tissues, and also, albeit at lower levels, in the corresponding non-tumor breast tissues (43). Hence, it is possible that CLN3 may also be overexpressed in non-tumor tissue surrounding the tumor. Discrepancy between CLN3 mRNA expression in non-tumor tissue surrounding the tumor and non-tumor tissue from reduction mammoplasties was calculated using the concordance correlation coefficient. There was poor concordance between non-tumor tissue surrounding the tumor and nontumor tissue from reduction mammoplasties $(\kappa=0.115)$ indicating that CLN3 gene expression in "morphologically" normal tissue derived from breast cancer patients is different from that of healthy individuals undergoing breast reduction surgery.

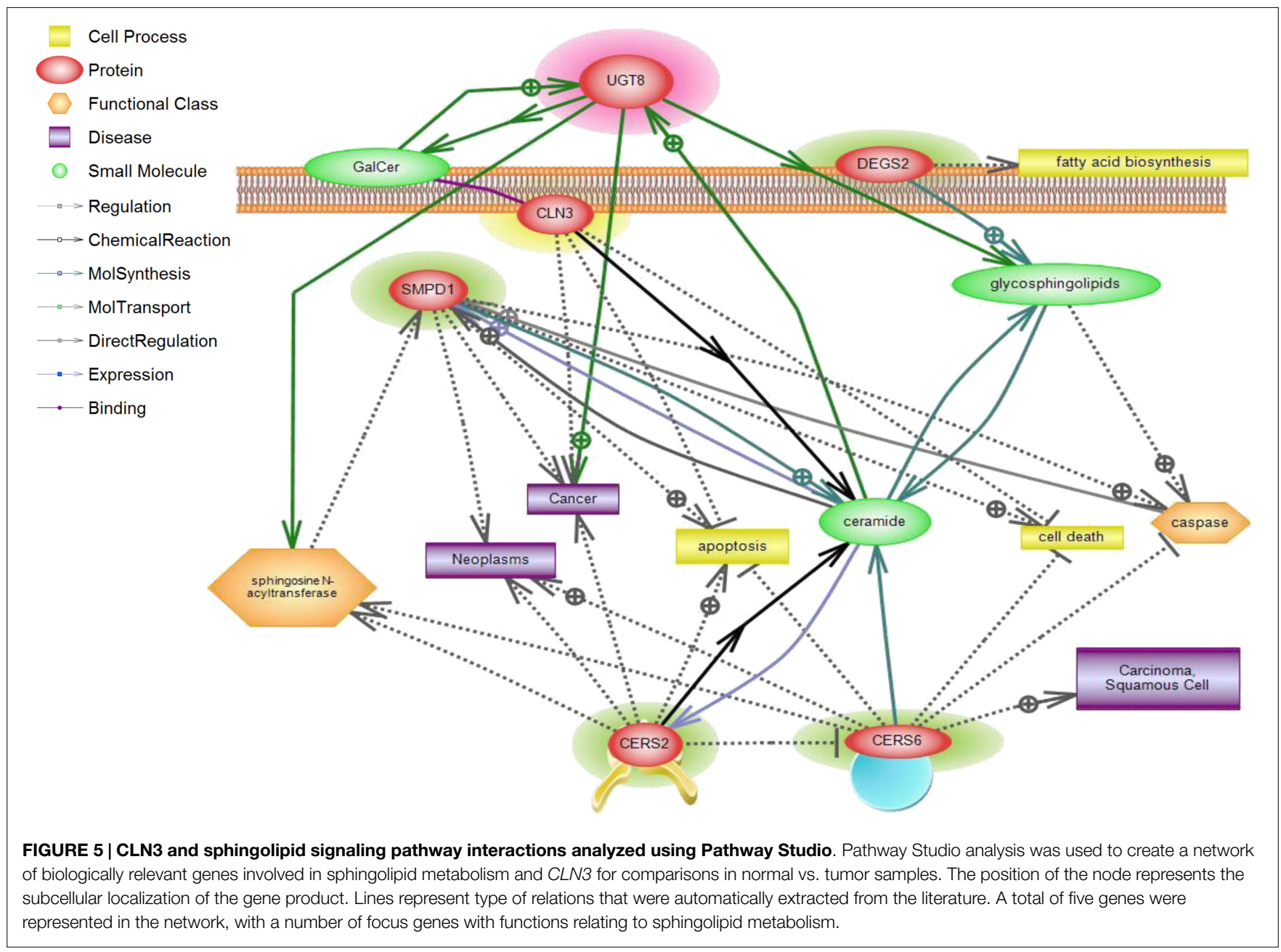


Non-tumor breast tissue from cancer patients, although normal at the clinical pathological level, is diseased at the molecular level. This finding carries important clinical consequences. After surgical removal of a tumor, there is still a high risk for tumor to develop in the same anatomical area. The new tumor has been traditionally explained by the growth of incompletely resected carcinomas. For cases where the tumor had been completely removed, according to pathology parameters, a genetically altered field at the molecular level remains and may be the cause of new cancer. The presence of a field with molecularly altered cells appears to be a risk factor for cancer. So, our results confirm the concept of field cancerization. In fact, data are widely available that cancer can develop from genetically altered cells in a field that was left behind in the patient after surgical removal of the initial carcinoma $(44,45)$.

In clinical practice, the elucidation of the association between gene expression profiles and clinicopathological characteristics may aid physicians in selecting patient-suitable treatments. Our findings confirm an association between high expression levels of the CLN3 gene and absence of HER2 expression in breast cancer patients, which increases the possibility of including it as a biomarker in breast cancer diagnostics. Good biomarkers can aid early cancer screening, confirm cancer diagnosis, predict outcome, tailor therapy, and guide future research directions by shedding light on new tumorigenesis pathways. The tools currently available to assess risk of progression of pre-invasive lesions to invasive ones are largely based on epidemiological data and patterns of progression across populations, with little guidance regarding individual risks for tumor progression. Fonsesca et al. show that in pre-invasive breast lesions, such as DCIS, the individual's risk of progression to IDC is unclear, yet surgery and other

\section{References}

1. Lee BL, Liedke PE, Barrios CH, Simon SD, Finkelstein DM, Goss PE. Breast cancer in Brazil: present status and future goals. Lancet Oncol (2012) 13:e95-102. doi:10.1016/S1470-2045(11)70323-0

2. Porter P. "Westernizing” women's risks? Breast cancer in lower-income countries. N Engl J Med (2008) 358:213-6. doi:10.1056/NEJMp0708307

3. Gaziano TA, Galea G, Reddy KS. Scaling up interventions for chronic disease prevention: the evidence. Lancet (2007) 370:1939-46. doi:10.1016/S01406736(07)61697-3

4. Beaglehole R, Ebrahim S, Reddy S, Voute J, Leeder S, Chronic Disease G. Action, prevention of chronic diseases: a call to action. Lancet (2007) 370:2152-7. doi:10.1016/S0140-6736(07)61700-0

5. El Saghir NS, Khalil MK, Eid T, El Kinge AR, Charafeddine M, Geara F, et al. Trends in epidemiology and management of breast cancer in developing Arab countries: a literature and registry analysis. Int J Surg (2007) 5:225-33. doi:10.1016/j.ijsu.2006.06.015

6. Doumit MA, El Saghir N, Abu-Saad Huijer H, Kelley JH, Nassar N. Living with breast cancer, a Lebanese experience. Eur J Oncol Nurs (2010) 14:42-8. doi:10.1016/j.ejon.2009.08.003

7. Lakkis NA, Adib SM, Osman MH, Musharafieh UM, Hamadeh GN. Breast cancer in Lebanon: incidence and comparison to regional and Western countries. Cancer Epidemiol (2010) 34:221-5. doi:10.1016/j.canep.2010.02.013

8. El Saghir NS, Shamseddine A, Geara F, Bikhaz K, Rahal B, Salem Z, et al. Breast cancer in Lebanon. Increased age-adjusted incidence rates in youngeraged groups at presentation: implications for screening and for Arab-American ethnic groups. Ethn Dis (2005) 15:S1-11.

9. Rusyn E, Mousallem T, Persaud-Sawin DA, Miller S, Boustany RM. CLN3p impacts galactosylceramide transport, raft morphology, and lipid content. Pediatr Res (2008) 63:625-31. doi:10.1203/PDR.0b013e31816fdc17 therapies seem to decrease the risk of invasive cancer (46). Also, in prostate and colon, pre-invasive lesions are much more common than aggressive cancers, and only $10 \%$ or less develop into invasive ones (47). Surgical and other interventions, now considered standard of care, might be excessive in a subset of lesions not destined to progress into aggressive phenotypes. Biomarkers can help select patients requiring intervention, and may allow targeted strategies to be developed for prevention of tumor progression.

A recent study demonstrated that acid ceramidase upregulation (a ceramide-metabolizing enzyme), is a conserved response to radiation therapy across multiple tumor types and acid ceramidase inhibition can directly improve the clinical response to radiotherapy in vitro and in vivo (48).

In conclusion, the expression of CLN3 is increased in human breast cancer. Moreover, several enzymes from the de novo ceramide synthesis pathway are differentially expressed in breast cancer, implicating ceramide and its upstream regulator, the CLN3 gene, in breast cancer.

CLN3 expression may be an additional useful biomarker and a novel molecular target for cancer drug discovery, the latter achieved via modulation of ceramide pathways.

\section{Acknowledgments}

This work was funded by MPP grant to RB MPP320046 and MPP grant to AT MPP320061.

\section{Supplementary Material}

The Supplementary Material for this article can be found online at http://journal.frontiersin.org/article/10.3389/fonc.2015.00215

10. Lerner T, Boustany R, Anderson J, D’Arigo K, Schlumpf K, Buckler A. Isolation of a novel gene underlying Batten disease, CLN3. The International Batten Disease Consortium. Cell (1995) 82:949-57.

11. Persaud-Sawin DA, Boustany RM. Cell death pathways in juvenile Batten disease. Apoptosis (2005) 10:973-85. doi:10.1007/s10495005-0733-6

12. Rylova SN, Amalfitano A, Persaud-Sawin DA, Guo WX, Chang J, Jansen PJ, et al. The CLN3 gene is a novel molecular target for cancer drug discovery. Cancer Res (2002) 62:801-8.

13. Persaud-Sawin DA, Mousallem T, Wang C, Zucker A, Kominami E, Boustany RM. Neuronal ceroid lipofuscinosis: a common pathway? Pediatr Res (2007) 61:146-52. doi:10.1203/pdr.0b013e31802d8a4a

14. Simstein R, Burow M, Parker A, Weldon C, Beckman B. Apoptosis, chemoresistance, and breast cancer: insights from the MCF-7 cell model system. Exp Biol Med (2003) 228:995-1003.

15. Ogretmen B, Hannun YA. Biologically active sphingolipids in cancer pathogenesis and treatment. Nat Rev Cancer (2004) 4:604-16. doi:10.1038/nrc 1411

16. Ruckhaberle E, Rody A, Engels K, Gaetje R, von Minckwitz G, Schiffmann S, et al. Microarray analysis of altered sphingolipid metabolism reveals prognostic significance of sphingosine kinase 1 in breast cancer. Breast Cancer Res Treat (2008) 112:41-52. doi:10.1007/s10549-007-9836-9

17. Team RDC. R: A Language and Environment for Statistical Computing. Vienna: The R Foundation for Statistical Computing (2011).

18. Irizarry RA, Bolstad BM, Collin F, Cope LM, Hobbs B, Speed TP. Summaries of Affymetrix GeneChip probe level data. Nucleic Acids Res (2003) 31:e15. doi:10.1093/nar/gng015

19. Smyth GK. Linear models and empirical bayes methods for assessing differential expression in microarray experiments. Stat Appl Genet Mol Biol (2004) 3:Article3. doi:10.2202/1544-6115.1027 
20. Benjamini Y, Hochberg Y. Controlling the false discovery rate: a practical and powerful approach to multiple testing. J R Stat Soc Series B Methodol (1995) 57:289-300.

21. Puranam KL, Guo WX, Qian WH, Nikbakht K, Boustany RM. CLN3 defines a novel antiapoptotic pathway operative in neurodegeneration and mediated by ceramide. Mol Genet Metab (1999) 66:294-308. doi:10.1006/mgme.1999. 2834

22. Cheng H, Qin Y, Fan H, Su P, Zhang X, Zhang H, et al. Overexpression of CARM1 in breast cancer is correlated with poorly characterized clinicopathologic parameters and molecular subtypes. Diagn Pathol (2013) 8:129. doi:10. 1186/1746-1596-8-129

23. Ross JS, Slodkowska EA, Symmans WF, Pusztai L, Ravdin PM, Hortobagyi GN. The HER-2 receptor and breast cancer: ten years of targeted anti-HER-2 therapy and personalized medicine. Oncologist (2009) 14:320-68. doi:10.1634/ theoncologist.2008-0230

24. Piccart-Gebhart MJ, Procter M, Leyland-Jones B, Goldhirsch A, Untch M, Smith I, et al. Trastuzumab after adjuvant chemotherapy in HER2-positive breast cancer. N Engl J Med (2005) 353:1659-72. doi:10.1056/NEJMoa052306

25. Marty M, Cognetti F, Maraninchi D, Snyder R, Mauriac L, Tubiana-Hulin $\mathrm{M}$, et al. Randomized phase II trial of the efficacy and safety of trastuzumab combined with docetaxel in patients with human epidermal growth factor receptor 2-positive metastatic breast cancer administered as first-line treatment: the M77001 study group. J Clin Oncol (2005) 23:4265-74. doi:10.1200/JCO. 2005.04.173

26. Baselga J, Seidman AD, Rosen PP, Norton L. HER2 overexpression and paclitaxel sensitivity in breast cancer: therapeutic implications. Oncology (1997) 11:43-8.

27. Zeidan YH, Hannun YA. Translational aspects of sphingolipid metabolism. Trends Mol Med (2007) 13:327-36. doi:10.1016/j.molmed.2007.06.002

28. Heering J, Weis N, Holeiter M, Neugart F, Staebler A, Fehm TN, et al. Loss of the ceramide transfer protein augments EGF receptor signaling in breast cancer. Cancer Res (2012) 72:2855-66. doi:10.1158/0008-5472.CAN-11-3069

29. Hannun YA, Obeid LM. Principles of bioactive lipid signalling: lessons from sphingolipids. Nat Rev Mol Cell Biol (2008) 9:139-50. doi:10.1038/ nrm2329

30. Ogretmen B, Hannun YA. Updates on functions of ceramide in chemotherapyinduced cell death and in multidrug resistance. Drug Resist Updat (2001) 4:368-77. doi:10.1054/drup.2001.0225

31. Reynolds CP, Maurer BJ, Kolesnick RN. Ceramide synthesis and metabolism as a target for cancer therapy. Cancer Lett (2004) 206:169-80. doi:10.1016/j.canlet. 2003.08.034

32. Erez-Roman R, Pienik R, Futerman AH. Increased ceramide synthase 2 and 6 mRNA levels in breast cancer tissues and correlation with sphingosine kinase expression. Biochem Biophys Res Commun (2010) 391:219-23. doi:10.1016/j. bbrc.2009.11.035

33. Michel C, van Echten-Deckert G, Rother J, Sandhoff K, Wang E, Merrill AH Jr. Characterization of ceramide synthesis. A dihydroceramide desaturase introduces the 4,5-trans-double bond of sphingosine at the level of dihydroceramide. J Biol Chem (1997) 272:22432-7. doi:10.1074/jbc.272.36.22432

34. Devlin CM, Lahm T, Hubbard WC, Van Demark M, Wang KC, Wu X, et al. Dihydroceramide-based response to hypoxia. JBiol Chem (2011) 286:38069-78. doi:10.1074/jbc.M111.297994

35. Kraveka JM, Li L, Szulc ZM, Bielawski J, Ogretmen B, Hannun YA, et al. Involvement of dihydroceramide desaturase in cell cycle progression in human neuroblastoma cells. J Biol Chem (2007) 282:16718-28. doi:10.1074/jbc.M700647200

36. Kim WJ, Okimoto RA, Purton LE, Goodwin M, Haserlat SM, Dayyani F, et al. Mutations in the neutral sphingomyelinase gene SMPD3 implicate the ceramide pathway in human leukemias. Blood (2008) 111:4716-22. doi:10.1182/blood2007-10-113068

37. Osawa Y, Suetsugu A, Matsushima-Nishiwaki R, Yasuda I, Saibara T, Moriwaki $\mathrm{H}$, et al. Liver acid sphingomyelinase inhibits growth of metastatic colon cancer. J Clin Invest (2013) 123:834-43. doi:10.1172/JCI65188

38. Corcoran CA, He Q, Ponnusamy S, Ogretmen B, Huang Y, Sheikh MS. Neutral sphingomyelinase- 3 is a DNA damage and nongenotoxic stress-regulated gene that is deregulated in human malignancies. Mol Cancer Res (2008) 6:795-807. doi:10.1158/1541-7786.MCR-07-2097

39. Dziegiel P, Owczarek T, Plazuk E, Gomulkiewicz A, Majchrzak M, PodhorskaOkolow $\mathrm{M}$, et al. Ceramide galactosyltransferase (UGT8) is a molecular marker of breast cancer malignancy and lung metastases. Br J Cancer (2010) 103:524-31. doi:10.1038/sj.bjc.6605750

40. van Geelen CM, Westra JL, de Vries EG, Boersma-van Ek W, Zwart N, Hollema $\mathrm{H}$, et al. Prognostic significance of tumor necrosis factor-related apoptosisinducing ligand and its receptors in adjuvantly treated stage III colon cancer patients. J Clin Oncol (2006) 24:4998-5004. doi:10.1200/JCO.2006.06.8809

41. Beckmann MW, Niederacher D, Schnurch HG, Gusterson BA, Bender HG. Multistep carcinogenesis of breast cancer and tumour heterogeneity. J Mol Med (1997) 75:429-39. doi:10.1007/s001090050128

42. Liu T, Zhang XY, He XH, Geng JS, Liu Y, Kong DJ, et al. High levels of BCOX1 expression are associated with poor prognosis in patients with invasive ductal carcinomas of the breast. PLoS One (2014) 9:e86952. doi:10.1371/journal.pone. 0086952

43. Song J, Yang W, Shih Ie M, Zhang Z, Bai J. Identification of BCOX1, a novel gene overexpressed in breast cancer. Biochim Biophys Acta (2006) 1760:62-9. doi:10.1016/j.bbagen.2005.09.017

44. Tabor MP, Brakenhoff RH, van Houten VM, Kummer JA, Snel MH, Snijders PJ, et al. Persistence of genetically altered fields in head and neck cancer patients: biological and clinical implications. Clin Cancer Res (2001) 7:1523-32. doi:10. 1016/j.bbagen.2005.09.017

45. Partridge M, Li SR, Pateromichelakis S, Francis R, Phillips E, Huang XH, et al Detection of minimal residual cancer to investigate why oral tumors recur despite seemingly adequate treatment. Clin Cancer Res (2000) 6:2718-25.

46. Fonseca R, Hartmann LC, Petersen IA, Donohue JH, Crotty TB, Gisvold JJ. Ductal carcinoma in situ of the breast. Ann Intern Med (1997) 127:1013-22. doi:10.7326/0003-4819-127-11-199712010-00013

47. Neugut AI, Jacobson JS, Rella VA. Prevalence and incidence of colorectal adenomas and cancer in asymptomatic persons. Gastrointest Endosc Clin N Am (1997) 7:387-99.

48. Cheng JC, Bai A, Beckham TH, Marrison ST, Yount CL, Young K, et al. Radiation-induced acid ceramidase confers prostate cancer resistance and tumor relapse. J Clin Invest (2013) 123:4344-58. doi:10.1172/JCI64791

Conflict of Interest Statement: Patent Methods of Screening for Risk of Proliferative Disease and Methods for the Treatment of Proliferative Disease. Inventors: Boustany et al., met filing requirements of the US Patent and Trademark Office on 1/23/2002 and assigned Serial No. 09/830,045 (US National Phase). Issued, June 6 2006; US Patent \# 60105262

Copyright (C) 2015 Makoukji, Raad, Genadry, El-Sitt, Makhoul, Saad Aldin, Nohra, Jabbour, Sangaralingam, Chelala, Habib, Boulos, Tfayli and Boustany. This is an open-access article distributed under the terms of the Creative Commons Attribution License (CC BY). The use, distribution or reproduction in other forums is permitted, provided the original author(s) or licensor are credited and that the original publication in this journal is cited, in accordance with accepted academic practice. No use, distribution or reproduction is permitted which does not comply with these terms. 